Subscriber access provided by Universidad de Alicante

\title{
Article
}

\section{On the Mobility and Oxidation of Adsorbed CO on Shape-Controlled Pt Nanoparticles in Acidic Medium}

Manuel J. S. Farias, Carlos Buso-Rogero, Francisco J. Vidal-

Iglesias, Jose Solla-Gullon, Giuseppe A Camara, and Juan M. Feliu

Langmuir, Just Accepted Manuscript • DOI: 10.1021/acs.langmuir.6b03612 • Publication Date (Web): 11 Jan 2017

Downloaded from http://pubs.acs.org on January 12, 2017

\section{Just Accepted}

"Just Accepted" manuscripts have been peer-reviewed and accepted for publication. They are posted online prior to technical editing, formatting for publication and author proofing. The American Chemical Society provides "Just Accepted" as a free service to the research community to expedite the dissemination of scientific material as soon as possible after acceptance. "Just Accepted" manuscripts appear in full in PDF format accompanied by an HTML abstract. "Just Accepted" manuscripts have been fully peer reviewed, but should not be considered the official version of record. They are accessible to all readers and citable by the Digital Object Identifier (DOI®). "Just Accepted" is an optional service offered to authors. Therefore, the "Just Accepted" Web site may not include all articles that will be published in the journal. After a manuscript is technically edited and formatted, it will be removed from the "Just Accepted" Web site and published as an ASAP article. Note that technical editing may introduce minor changes to the manuscript text and/or graphics which could affect content, and all legal disclaimers and ethical guidelines that apply to the journal pertain. ACS cannot be held responsible for errors or consequences arising from the use of information contained in these "Just Accepted" manuscripts. 


\title{
On the Mobility and Oxidation of Adsorbed CO on Shape-
}

\section{Controlled Pt Nanoparticles in Acidic Medium}

\author{
Manuel J. S. Farias ${ }^{* \dagger}$, Carlos Busó-Rogero ${ }^{\ddagger}$, Francisco J. Vidal-Iglesias ${ }^{\ddagger}$, José Solla- \\ Gullón $^{2}$, Giuseppe A. Camara ${ }^{\S}$ Juan M. Feliu* \\ ${ }^{\dagger}$ Departamento de Química, Universidade Federal do Maranhão, Avenida dos \\ Portugueses, 1966, CEP 65080-805, São Luís - MA, Brazil \\ *Instituto de Electroquímica, Universidad de Alicante Ap. 99, E-03080, Alicante, Spain \\ ${ }^{\S}$ Instituto de Química, Universidade Federal de Mato Grosso do Sul, C.P. 549, 79070- \\ 900, Campo Grande, Brazil
}

\begin{abstract}
The knowledge about how $\mathrm{CO}$ occupies and detaches from specific surface sites on well-structured Pt surfaces provides outstanding information on both dynamics/mobility of $\mathrm{CO}_{\mathrm{ads}}$ and oxidation of this molecule under electrochemical conditions. This work reports how the potentiostatic growth of different coverage $\mathrm{CO}$ adlayers evolves with time on both cubic and octahedral Pt nanoparticles in acidic medium. Data suggest that during the growth of the $\mathrm{CO}$ adlayer, $\mathrm{CO}_{\mathrm{ads}}$ molecules slightly shift towards low coordination sites only on octahedral Pt nanoparticles, so that these under coordinated sites are the first filled on octahedral Pt nanoparticles. Conversely, on cubic Pt nanoparticles, adsorbed $\mathrm{CO}$ behaves as an immobile species, and low coordinated sites, as well as (100) terraces are apparently filled uniformly and simultaneously. However, once the adlayer is complete, irrespectively of whether the $\mathrm{CO}$ is oxidized in a single
\end{abstract}


step or in a sequence of different potential steps, results suggest that $\mathrm{CO}_{\mathrm{ads}}$ behaves as an immobile species during its oxidation on both octahedral and cubic Pt nanoparticles.

Keywords: Shape-controlled Pt nanoparticles, CO oxidation, surface chemical reaction, surface diffusion.

*Author to whom correspondence should be addressed: manueljsfarias@gmail.com (M.J.S. Farias); Phone: +55 9833018246 


\section{Introduction}

The adsorption and oxidation reactions of carbon monoxide (CO) on well-defined surfaces are considered model reactions in surface electrochemistry and electrocatalysis. Thus, for instance, adsorption of $\mathrm{CO}$ is useful for obtaining information about the structure of the electrochemical interface (for example in determination of the potential of zero total charge). ${ }^{1}$ Also, carbon monoxide is almost ubiquitous since it appears many times as an intermediate species during the electro-oxidation of alcohols (as methanol, ethanol, etc. $)^{2}$ in low temperature alcohol fuel cells and is even present as an impurity in the electro-oxidation of hydrogen (from catalytic reforming) used in proton exchange membrane fuel cells. The overall performance of a fuel cell, in turn, greatly depends on the catalytic activity, selectivity and stability of those materials used as electrodes (cathode and anode). In this context, the tolerance to $\mathrm{CO}$ (present either as an intermediate of reaction or an impurity) has been considered a key-aspect in the performance of a specific anode in studies involving fuel cells. ${ }^{3}$ Interestingly, the CO electro-oxidation is known to be a surface structure sensitive reaction, i.e., a reaction markedly influenced by the particular arrangement of the atoms at the surface of the catalyst, $^{4-6}$ (and also by the size of the sample in the case of catalysts consisting of nanoparticles ${ }^{7}$ ). Such sensitivity motivates the study of this reaction in shape-controlled catalysts, whose surface structure is ordered and allows more detailed mechanistic information.

In most cases, dissolved molecular $\mathrm{CO}$ is adsorbed on the surface at a fixed potential, the excess of $\mathrm{CO}$ in solution is removed and then the $\mathrm{CO}_{\mathrm{ads}}$ adlayer is oxidized (in absence of $\mathrm{CO}$ in solution) by either voltammetric or chronoamperometric protocols. The overall $\mathrm{CO}$ electro-oxidation reaction in sulfuric acid can be represented as: 


$$
\mathrm{Pt}_{\alpha}-\mathrm{CO}+\mathrm{Pt}_{\gamma^{-}}\left(\mathrm{H}_{2} \mathrm{O}\right) \rightarrow \mathrm{CO}_{2}+2 \mathrm{H}^{+}+2 e^{-}+(\alpha+\gamma) \mathrm{Pt}
$$

where $\alpha$ and $\gamma$ indicate the number of Pt sites involved in the adsorption of each species. Step (1) is followed by a fast regeneration of the electric double layer at the clean $\mathrm{Pt}$ sites liberated at the stripping potential:

$$
n \mathrm{Pt}+\mathrm{HSO}_{4}^{-} \rightarrow \mathrm{Pt}_{n^{-}}\left(\mathrm{SO}_{4}\right)+\mathrm{H}^{+}+2 e^{-}
$$

In reaction (1) $\mathrm{CO}_{2}$ results from a bimolecular collision between neighboring $\mathrm{CO}_{\mathrm{ads}}$ and likely adsorbed oxygen donors stemming from (activated) water in a Langmuir-Hinshelwood mechanism (L-H) type, as proposed by Gilman in $1964{ }^{8}$ At aqueous solid/liquid interfaces, the oxygen donors species coming from any sort of activated water, including on-site electrochemically generated $\mathrm{Pt}_{y^{-}}-\left(\mathrm{H}_{2} \mathrm{O}\right)$ (see below) are virtually infinite compared to the amount of $\mathrm{CO}_{\text {ads }}$ on the surface, as water molecules are always omnipresent species at the electrode/aqueous $\left(\mathrm{Pt}_{\alpha}-\mathrm{CO} /\right.$ aqueous $)$ interface.

In the so-called CO stripping experiments, non-adsorbed $\mathrm{CO}$ is removed from the solution and therefore there is no $\mathrm{CO}$ external supply to the surface. Thus, the distribution of adsorbed reactants, and their dynamics/mobility relative to the active sites are important questions that should be properly addressed for a better understanding of how the reaction proceeds. For instance, some studies ${ }^{9-10}$ assume that $\mathrm{CO}_{\text {ads }}$ and likely $\mathrm{OH}_{\mathrm{ads}}\left(\mathrm{Pt}-\mathrm{H}_{2} \mathrm{O} \rightleftarrows \mathrm{Pt}-\mathrm{OH}_{\mathrm{ads}}+\mathrm{H}^{+}+e^{-}\right)$are perfectly mixed on the surface, and that the $\mathrm{CO}_{\text {ads }}$ diffusion coefficient is higher than its oxidation rate, which implies that the reaction is proportional to the average coverage of both $\mathrm{CO}_{\mathrm{ads}}\left(\theta_{\mathrm{CO}}\right)$ and $\mathrm{OH}_{\mathrm{ads}}\left(\theta_{\mathrm{OH}}\right)$. These assumptions satisfy the Mean Field Approximation conditions in a L-H mechanism type. ${ }^{11}$ Incidentally, in most cases, a high $\mathrm{CO}_{\mathrm{ads}}$ surface diffusion is expected since it is claimed that $\mathrm{CO}_{\text {ads }}$ oxidation preferentially takes place on low coordination sites, ${ }^{5-7,10,12-16}$ as corner/step/kink/ad-atom sites. However, this fact does 
not appear to be consistent with recent contributions that show that the intrinsic catalytic activity of low coordinated sites (steps/kinks) to the $\mathrm{CO}$ electro-oxidation is smaller than the catalytic activity of the rest of sites present on catalyst surfaces, as the $\{111\}$ terrace sites, no matter if such reaction is evaluated in acid or in alkaline solutions. ${ }^{17-18}$

On the other hand, the Nucleation and Growth $(\mathrm{N} \& \mathrm{G})$ model assumes that $\mathrm{CO}_{\mathrm{ads}}$ is a motionless species and that its oxidation takes place when domains of adsorbed oxygen-donors grow from the vacancies of a CO adlayer. ${ }^{19}$ Hence, the presence of these $\mathrm{CO}_{\mathrm{ads}}$ superstructures on Pt single crystals has been evidenced by in situ STM. ${ }^{20,21}$ Furthermore, Weaver et al. investigated how the $\mathrm{CO}_{\text {ads }}$ stretching frequencies depend on $\theta_{\mathrm{CO}}$ (achieved whether by partial stripping from a saturated $\mathrm{CO}$ adlayer or by direct dosing) for various ${ }^{12} \mathrm{CO} /{ }^{13} \mathrm{CO}$ mixtures on $\mathrm{Pt}(111)$ by using in situ FTIRS. ${ }^{22}$ Results were interpreted in terms of the formation of $\mathrm{CO}_{\text {ads }}$ islands, whose oxidation starts at their edges. ${ }^{22}$

Now let us revisit what happens during the electro-oxidation of $\mathrm{CO}$ on nanoparticles, which have an unequivocal practical appeal. On polyoriented $\mathrm{Pt}$ nanoparticles, Maillard et $a .^{7}$ proposed that particles smaller than $2 \mathrm{~nm}$ restrict the mobility of $\mathrm{CO}_{\text {ads }}$, and assumed that $\mathrm{CO}$ oxidation occurs at the edges/corners of the particles, in agreement with previous findings dealing with the $\mathrm{CO}$ electro-oxidation on Pt stepped surfaces. ${ }^{10}$ On the other hand, on shape-controlled Pt nanoparticles (of $\sim 9-15$ $\mathrm{nm}$ ) in acidic medium, Coutanceau et al. ${ }^{23}$ suggested very low mobility of $\mathrm{CO}_{\mathrm{ads}}$ on $2 \mathrm{D}$ $\{100\}$ structures on cubic nanoparticles. In addition, as proposed for $\mathrm{CO}$ oxidation on $\mathrm{Pt}$ single crystals, ${ }^{10}$ they claimed that during $\mathrm{CO}$ oxidation, $\mathrm{CO}_{\mathrm{ads}}$ on $\{111\}$ terraces quickly diffuses toward low coordination sites where it is preferentially oxidized, ${ }^{23}$ as already proposed for $\mathrm{CO}$ oxidation on Pt single crystals in acid solution. ${ }^{6,10}$ As occurs with Pt stepped surfaces, ${ }^{6}$ the catalytic activity of Pt nanoparticles is found to increase 
with the density of step sites, ${ }^{24}$ despite the mechanism by which under-coordinated sites affect this reaction is not fully understood yet. Brimaud et $a l^{25}$ in a study of assignation of surface sites for the CO stripping voltammetry on $\{100\}$ preferentially oriented $\mathrm{Pt}$ nanoparticles also considered plausible that during its oxidation, $\mathrm{CO}$ attached on $\{111\}$ terraces migrates towards low coordinated sites, as $\{110\}$ sites, similar to that proposed for stepped Pt surfaces in acid solution. ${ }^{5}$ In turn, for stepped Pt single crystals, it has been recently shown that the sequence in which the sites are set free during the stripping of a $\mathrm{CO}$ adlayer might be governed by a site activation process ${ }^{17}$ that must have strong implications on the mobility of $\mathrm{CO}_{\mathrm{ads}}$ during its oxidation. In this sense, questions about the dynamic/mobility of $\mathrm{CO}_{\text {ads }}$ during the growth of layer as well as during its oxidation need to be considered, and new experimental and theoretical approaches are still required to reach a full understanding of this crucial step of this important electrochemical reaction.

In this contribution, we report new experimental evidences about the behavior of the growth of a $\mathrm{CO}$ sub-adlayer on different shape-controlled Pt nanoparticles at constant potential, followed by its subsequent oxidation through a successive step potential program.

\section{Experimental}

Cubic and octahedral shape-controlled Pt nanoparticles were synthesized using a colloidal method. ${ }^{26}$ Details about the synthesis and physical characterization of the nanoparticles including particle size $(\sim 8 \mathrm{~nm})$ and morphology/shape of the particles can

be found in the Supporting Information and also in previous contributions ${ }^{27-28}$ (and references therein). The nanoparticles were deposited on a polished gold disk, being 
used as working electrode. The electroactive surface area of the nanoparticles was calculated as described elsewhere. ${ }^{1}$ A Pt wire was used as counter-electrode and a reversible hydrogen electrode (RHE) was employed as reference electrode. CO (Alpha Gas, $99.997 \%$ ) was adsorbed at $0.10 \mathrm{~V}$ and non-adsorbed $\mathrm{CO}$ was eliminated from the solution by bubbling Ar (Alpha Gaz ${ }^{\mathrm{TM}}$ 99.999\%) for about 35 minutes. Studies of CO site occupancy were performed in presence of $\mathrm{CO}$ in the solution, while potential step experiments were carried out in the absence of $\mathrm{CO}$ in the solution. A $0.5 \mathrm{M} \mathrm{H}_{2} \mathrm{SO}_{4}$ solution (Merck KGaA 96\%) prepared in ultrapure water (Milli-Q 18.2 M $\Omega \mathrm{cm}$ ) was used in all the experiments, which were performed at room temperature $\left(22-25^{\circ} \mathrm{C}\right)$.

\section{Results}

\subsection{Site occupancy during slow growth of CO sub-adlayer}

Figure 1 shows characteristic voltammetric responses of cubic and octahedral shape-controlled Pt nanoparticles recorded in $\mathrm{H}_{2} \mathrm{SO}_{4}$ solution. Voltammetric features are in good agreement with the fact that the cubic particles should expose mainly $\{100\}$ facets, while the octahedral ones should present an important contribution of $\{111\}$ facets. ${ }^{29}$ Particularly, the voltammetric peaks at $\sim 0.13$ and $\sim 0.27 \mathrm{~V}$ are due to hydrogen adsorption/desorption on under-coordinated sites as on $\{110\}$ sites $(\{111\}$ steps, defects) and $\{100\}$ steps and small domains, respectively. ${ }^{26}$ In addition, for cubic Pt nanoparticles, the contributions between $0.30-0.43 \mathrm{~V}$ are associated to hydrogen adsorption/desorption on relatively wide $2 \mathrm{D}\{100\}$ terraces. ${ }^{26}$ Finally, for octahedral nanoparticles (Figure 1B) contribution in the range $0.1-0.35 \mathrm{~V}$ is due to hydrogen adsorption/desorption on $\{111\}$ terraces, and the reversible feature between $0.43 \mathrm{~V}$ and $0.63 \mathrm{~V}$ is unequivocally due to the sulfate adsorption on $2 \mathrm{D}\{111\}$ terrace domains. ${ }^{26}$ In 
a general way, the voltammetric profiles shown in Figure 2 are virtually identical to those results observed for shape-controlled nanoparticles in similar conditions (sulfuric acid). ${ }^{30-31}$ It is important to highlight that different upper potential limits were used during the recording of cyclic voltammograms (Figure 1) in order to avoid irreversible surface roughening induced by the electrode potential.

Figures $2 \mathrm{~A}$ and $2 \mathrm{C}$ show the evolution of the cyclic voltammograms recorded after potentiostatic growth (at $0.10 \mathrm{~V}$ ) of a $\mathrm{CO}$ sub-adlayer on both samples of $\mathrm{Pt}$ nanoparticles. The control of CO dosing experiment was performed by passing a diluted $\mathrm{CO}$ gas flow $(\sim 1 / 10 \mathrm{CO} / \mathrm{Ar})$ and keeping it in the cell atmosphere for different times, which corresponds to different $\theta_{\mathrm{CO}}$ (non-adsorbed $\mathrm{CO}$ was not eliminated from the solution). Subsequently, cyclic voltammetries were recorded at a relatively fast rate of $0.2 \mathrm{~V} \mathrm{~s}^{-1}$, controlling the upper limit to avoid CO stripping. At this scan rate, each cycle lasts only $\sim 4 \mathrm{~s}$, and consequently the interference from dissolved $\mathrm{CO}$ in Figure 2 can be considered negligible. In order to calculate the $\mathrm{CO}$ coverage, we considered that the suppression of hydrogen region reflects well the $\mathrm{CO}$ coverage until $\theta_{\mathrm{CO}} \simeq 0.55$. $^{32}$ Also, we assume that a $\mathrm{CO}$ saturated adlayer $\left(\theta_{\mathrm{CO}, \max }\right)$ was equivalent to $\sim 0.72$ and $\sim 0.66$ for cubic Pt nanoparticles and octahedral ones, respectively. ${ }^{33}$ For cubic nanoparticles the charge of hydrogen (in absence of adsorbed $\mathrm{CO}$ ) was integrated between $0.06 \mathrm{~V}$ and $0.46 \mathrm{~V}$ resulting in $\sim 266 \mu \mathrm{C} \mathrm{cm}^{-2}$, while for octahedral Pt nanoparticles the same procedure has resulted in a charge density of $\sim 207 \mu \mathrm{C} \mathrm{cm}^{-2}$.

In Figure 2A, the occupancy of sites on cubic Pt nanoparticles reduces the current uniformly along the voltammogram. For example, when $\mathrm{CO}$ exposure time is $22 \mathrm{~s}$ (which corresponds to $\theta_{\mathrm{CO}} \simeq 0.07$ ), the overall current feature is diminished, but the voltametric profile is similar to that in absence of $\mathrm{CO}$ in solution. Even with $\theta_{\mathrm{CO}} \simeq 0.57$ (89 s of CO exposure) we can observe that the feature due to the hydrogen 
adsorption/desorption in under-coordinated sites still survives. A similar trend can be observed for octahedral Pt nanoparticles (Figure 2C), but for intermediate CO coverage $\left(82 \mathrm{~s}, \theta_{\mathrm{CO}} \simeq 0.43\right)$ the under-coordinated sites are almost entirely blocked.

In order to better visualize the relative $\mathrm{CO}$ occupancy on the different sites for several $\mathrm{CO}$ dosing times (or $\theta_{\mathrm{CO}}$ ), each voltammetric cycle in Figures $2 \mathrm{~A}$ and $2 \mathrm{C}$ was multiplied by an arbitrary factor, in such a way that the current density at $0.20 \mathrm{~V}$ would be the same as that measured in the blank voltammogram (in absence of $\mathrm{CO}$ in the solution). At this potential, a relatively large current is recorded and it is located between two peaks for both types of Pt nanoparticles. The results of such normalization procedure are displayed in Figures $2 \mathrm{~B}$ and $2 \mathrm{D}$. While figure $2 \mathrm{~B}$ suggests an uniform surface blockage, Figure 2D shows that the feature at $0.27 \mathrm{~V}$ is preferentially blocked.

\subsection{Current-time analysis}

For the analysis of the current-time curves, a full $\mathrm{CO}$ adlayer was prepared at 0.10 $\mathrm{V}$ and non-adsorbed $\mathrm{CO}$ was eliminated from the solution for $35 \mathrm{~min}$ by bubbling Ar. Hence, two different potential protocols were evaluated. In Figures 3A and 3D, corresponding to cubic and octahedral nanoparticles, respectively, the potential was stepped from 0.10 to $0.65 \mathrm{~V}$ to completely remove the $\mathrm{CO}$ adlayer at once. Other electrode potentials were also tested for the chronoamperometric $\mathrm{CO}$ oxidation (not shown), but it was verified that transients were either too fast (when the electrode potential was high as $0.67 \mathrm{~V}$, resulting in a very short time for the occurrence of maximum current) or too slow (when the electrode potential was $0.63 \mathrm{~V}$, for which current maxima were not well defined). Alternatively, in Figure 3B (cubic nanoparticles) and Figure 3E (octahedral nanoparticles), a second potential protocol was 
used and the potential was alternated between $0.10 \mathrm{~V}$ and an upper potential of $0.65 \mathrm{~V}$, as $0.10 \rightarrow 0.65 \rightarrow 0.10 \rightarrow 0.65 \mathrm{~V} \ldots$, in several short time sequences to allow removal of successive portions of adsorbed $\mathrm{CO}$.

The current-time curve reported in Figure $3 \mathrm{~A}$ for $\mathrm{CO}$ oxidation (after a single potential step) on cubic nanoparticles shows a transient spike at very short times, followed by a current decay which culminates in a local minimum before generating a further rise of current, peaking at $t_{1, \max } \simeq 2.8 \mathrm{~s}$. Later, a second current maximum is reached (only for cubic nanoparticles) at $t_{2, \max } \simeq 48.0 \mathrm{~s}$. Because the formation of $\mathrm{CO}_{2}$ results from a bimolecular collision between neighboring $\mathrm{CO}_{\text {ads }}$ and oxygen-containing species, according to the equation 1 , each molecule of $\mathrm{CO}_{2}$ formed involves the release of (at least) two available sites for the adsorption of oxygen-containing species, which can accelerate the rate of $\mathrm{CO}$ oxidation. In this sense, the maximum current on currenttime curves results from gradual increases in available sites for the oxygen-containing species, whose optimal condition for maximum rate reaction depends on certain conditioning coverage of reactants (size of nano-domains of reactants on surface). We believe that the existence of two maximum currents likely point out to two decoupled kinetic processes on the same catalytic surface, whose origin needs to be further investigated. For the oxidation of $\mathrm{CO}$ on octahedral Pt nanoparticles by a single potential step (Figure 3 D), the current-time curve only shows a single maximum current at $t_{1, \max } \simeq 5.0 \mathrm{~s}$. In case of the CO adlayer oxidation by multiple potential steps, for sake of a better visualization of the current-time curves, the time portions collected at $0.10 \mathrm{~V}$ (current was essentially zero) were eliminated from Figures $3 \mathrm{~B}$ and $3 \mathrm{E}$, generating the condensed multiple step curves displayed in Figures 3C and 3F, for cubic and octahedral nanoparticles, respectively. As it can be seen in Figures $3 \mathrm{C}$ and $3 \mathrm{~F}$, the coincidence with their corresponding single transient (3A and $3 \mathrm{D}$, respectively) is quite 
remarkable for both samples of nanoparticles. In this respect, it is important to mention that using this multiple potential steps to $0.10 \mathrm{~V}$ imply the re-adsorption of hydrogen which could hinder a possible CO reorganization. In order to avoid this possible interference, we performed similar experiments in which the potential was initially stepped from $0.10 \mathrm{~V}$ to $0.65 \mathrm{~V}$ (where the $\mathrm{CO}$ oxidation reaction takes place), and then successively alternated between $0.65 \rightarrow 0.45 \rightarrow 0.45 \rightarrow 0.65 \mathrm{~V} \ldots$. It is worth noting that at this new potential of $0.45 \mathrm{~V}$, the rate of $\mathrm{CO}$ oxidation reaction is still negligible. Moreover, at this potential hydrogen is desorbed and sulfate is not yet adsorbed on the $\{111\}$ terraces. The results are displayed in Figure 4, for cubic (Figure $4 \mathrm{~A}$ ) and octahedral (Figure 4 C) Pt nanoparticles. Again, the time portions collected at $0.45 \mathrm{~V}$ (current essentially zero) were eliminated from the Figures $4 \mathrm{~A}$ and $4 \mathrm{C}$, resulting in condensed multiple step curves displayed in Figures 4B and 4D. By comparing these two potential programs, we can see that both protocols provide similar current-time curves, independently of the sample used. Thus, for cubic nanoparticles, Figure 4B results almost identical than that displayed in Figures $3 \mathrm{~A}$ and $3 \mathrm{C}$ while, for octahedral Pt nanoparticles, Figure 4D, the results are similar to that shown in Figure 3D or 3F.

\section{Discussion}

The results reported in Figure 2B show that during the growth of the $\mathrm{CO}$ adlayer, that is, for increasing $\theta_{\mathrm{CO}}$, the normalized voltammetric profiles of the cubic $\mathrm{Pt}$ nanoparticles reproduce the whole voltammetric profile for all CO coverage, i.e., the normalized cyclic voltammograms are very similar to that corresponding to the surface free of $\mathrm{CO}$ (no exposure). Because at the potential in which the adsorption of $\mathrm{CO}$ was performed $(0.10 \mathrm{~V})$ only hydrogen is on the Pt surface. Accordingly, a displacement reaction takes place: $\mathrm{CO}_{\text {solution }}+\mathrm{H}_{\mathrm{ads}} \rightarrow \mathrm{CO}_{\mathrm{ads}}+\mathrm{H}^{+}+e^{-}$. This means that all available 
sites for hydrogen adsorption/desorption are blocked in a uniform way at the surface. In this case, even when the surface has been almost fully blocked by $\mathrm{CO}$ (for example $\theta_{\mathrm{CO}}$ $\simeq 0.57$ ), the normalized voltammetric profile in Figure $2 \mathrm{~B}$ remains similar to that in absence of CO. These observations suggest that during $\mathrm{CO}$ adsorption, the occupancy (site blockage) of the under-coordinated sites and wide 2D $\{100\}$ terraces is essentially uniform, i.e., this process occurs involving all surface sites apparently without preferential adsorption even when surface is almost fully blocked $\left(\theta_{\mathrm{CO}} \simeq 0.57\right)$ and just slightly higher than the other surface sites. Consequently, once there is no preferential $\mathrm{CO}$ adsorption, this apparent uniform fill of sites implies a low mobility of the $\mathrm{CO}_{\mathrm{ads}}$ from the $2 \mathrm{D}\{100\}$ domains to the low coordination sites on cubic Pt nanoparticles. At this point, by a different methodology (and analysis), our results are in agreement with those of Coutanceau et al. ${ }^{23}$ for similar shaped nanoparticles with average size $\sim 12 \mathrm{~nm}$. On the other hand, for another type of nanostructured material, tetrahexahedral $\mathrm{Pt}$ nanoparticles containing $[3(100) \times(110)+2(100) \times(110)]$ facets (particles size $\sim 54 \mathrm{~nm}$ ) electrochemically prepared on glassy carbon, Liu et al. ${ }^{34}$ recently reported a CO adsorption study and concluded that at low $\mathrm{CO}$ coverage $\left(\theta_{\mathrm{CO}}<0.088\right), \mathrm{CO}$ adsorbs preferentially on $\{100\}$ sites, which implies a shift of the adsorbed CO during the growth of the adlayer towards these sites.

The situation is slightly different for the octahedral Pt nanoparticles, as shown in Figure $2 \mathrm{D}$. After $102 \mathrm{~s}$ of exposure to dissolved $\mathrm{CO}\left(\theta_{\mathrm{CO}} \simeq 0.56\right)$, we observe that the under-coordinated sites are proportionally more blocked than $\{111\}$ terraces (Figure 2D), and sites assigned as $\{100\}$ sites at $0.27 \mathrm{~V}$ are blocked first than the rest of surface sites. These data suggest that in octahedral Pt nanoparticles, in contrast with the cubic ones, $\mathrm{CO}$ is preferentially adsorbed on low coordination sites, which in turn suggests a different mobility of $\mathrm{CO}_{\mathrm{ads}}$ on $\{111\}$ terraces than on $\{100\}$ ones. Namely, under- 
coordinated sites are firstly blocked by CO than those of $\{111\}$ terraces, in contrast with the fact that $\mathrm{CO}$ (from the solution) reaches all kind of sites simultaneously. This observation means that $\mathrm{CO}_{\text {ads }}$ molecules from $\{111\}$ terraces likely diffuse to undercoordinated sites during the growth of a CO adlayer on octahedral Pt nanoparticles.

Now let us compare the site occupancy on cubic and octahedral Pt nanoparticles at similar $\mathrm{CO}$ coverage by taking the corresponding voltammetric features at $\theta_{\mathrm{CO}} \simeq 0.49$ (cubic) and $\theta_{\mathrm{CO}} \simeq 0.43$ (octahedral). Even when the $\mathrm{CO}$ coverage on octahedral $\mathrm{Pt}$ nanoparticles is slightly smaller than on cubic ones, Figure $2 \mathrm{D}$ shows that almost all the under-coordinated sites on octahedral nanoparticles are fully covered by $\mathrm{CO}$, while for the cubic ones the discharge of hydrogen remains discernible in under-coordinated sites. However, the situation of $\theta_{\mathrm{CO}} \simeq 0.57$ on for cubic samples and $\theta_{\mathrm{CO}} \simeq 0.56$ on octahedral ones evidence that all under-coordinated sites at octahedral nanoparticles are blocked (Figure 2D), while for cubic nanoparticles is still possible to distinguish the feature of under-coordinated sites available for hydrogen adsorption/desorption (Figure 2B). Based on such relative differences in the behavior of CO site occupancy (for similar CO coverage) we suggest that exists a relative higher mobility of $\mathrm{CO}_{\mathrm{ads}}\{111\}$ terraces than on $\{100\}$ one during the growth of the CO layer. It is noteworthy to remark that the pattern of CO site occupancy in octahedral sites (terraces, and low coordinated sites) is similar to that already observed for the CO site occupancy in similar nanoparticles sample in alkaline media ${ }^{27}$ and also in the family of stepped $\operatorname{Pt}(\mathrm{s})-[(n-1)(111) \times(110)]$ single crystals in acidic media. ${ }^{35}$

For the CO oxidative stripping in acid media, the current vs. time profile coming from multiple potential steps experiments provides information about the dynamic/mobility of $\mathrm{CO}_{\mathrm{ads}}$ in the adlayer during its oxidation. ${ }^{18}$ The results shown in Figures 3 and 4 point out that current $v s$. time profile is almost independent on the 
potential step protocol. Thus, when the potential is successively stepped from $0.10 \mathrm{~V}$ to $0.65 \mathrm{~V}$, results in Figures $3 \mathrm{C}$ and 3F suggest that the oxidation of $\mathrm{CO}$ layer apparently continues exactly from the same point at which the process was stopped, regardless of the sequence of steps previously performed. This points out to an apparently immobility or a unchanged distribution of reactants on surface, because the kinetics of a surface reaction deeply depends on how the reactants are distributed at the surface ${ }^{36-38}$ and our data suggest that the organization of $\mathrm{CO}_{\mathrm{ads}}$ in remaining layer is not significantly affected during the successive potential steps shown in Figures 3 and 4. At first glance, we might think that this apparent immobility of $\mathrm{CO}$ in the remaining layer is because the electrode potential was stepped to a potential where $\mathrm{CO}$ free $\mathrm{Pt}$ surface sites are immediately occupied by hydrogen (with high $\mathrm{H}_{\text {ads }}$ coverage), which could act as a barrier for $\mathrm{CO}$ surface diffusion. However, the experiments shown in Figure 4, in which the electrode potential was stepped from $0.65 \mathrm{~V}$ to $0.45 \mathrm{~V}$ (a potential at which the surface free of adsorbed hydrogen and adsorbed anions) also suggest that adsorbed CO remains as an immobile species during its oxidation. This finding differs from previous contributions, ${ }^{7,23}$ in which it was claimed that during the $\mathrm{CO}$ adlayer oxidation, $\mathrm{CO}_{\mathrm{ads}}$ molecules quickly move from $\{111\}$ terraces to low coordination sites (claimed to be the most active sites), or CO on any sites of polyoriented Pt nanoparticles must move to edges/corners, where reaction could takes place. This behavior clearly indicates a lack of mobility of $\mathrm{CO}_{\mathrm{ads}}$ during its oxidation, which results in a very similar current-time profile, regardless of whether the oxidation is performed in a single or in multiple steps.

A probable reason why $\mathrm{CO}$ behaves as an immobile species during the growth of a CO adlayer can only tentatively linked to a possible large difference in reactivity (sticking coefficient) in under-coordinated sites (as corners, steps, ad-atoms, etc.) compared to the reactivity in close-packed domains. Also, the diffusion can be 
influenced by the lateral interaction present in the adsorbate layer. In fact, as examined for stepped Pt surfaces, $\mathrm{CO}$ adsorbs more strongly in under-coordinated sites than in terrace sites ${ }^{39-42}$, and the rate of CO filling on under-coordinated is higher as higher is the overall CO coverage. ${ }^{35}$ The argument above can be employed, at least in part, to justify why the $\mathrm{CO}_{\mathrm{ads}}$ does behave like an immobile species during its oxidation. Namely, once CO oxidation starts on those sites where it is weakly bonded, ${ }^{17}$ it seems unlikely that remaining CO shift from any other sites to those less catalytic ones (where the bond CO-surface is stronger). Moreover, when $\mathrm{CO}$ is oxidized, the lateral interaction exerted by neighboring adsorbed molecules diminishes, because the average distance among them increases. In addition, the attachment of $\mathrm{CO}$ in sites with low chemical reactivity (which in case of $\mathrm{CO}$ electro-oxidation coincides with those sites of high catalytic activity) is favored when the electrode surface is negatively charged (at potentials below $0.3 \mathrm{~V}_{\mathrm{RHE}}$ ) and not at potentials above $0.5 \mathrm{~V}_{\mathrm{RHE}}$, at which the $\mathrm{CO}$ electro-oxidation occurs ${ }^{18}$. In this sense, it is plausible that adsorbed CO behaves as an immobile species during its oxidation at $\mathrm{Pt} /$ aqueous electrochemical interface.

Hence, our results can be rationalized as follows: providing that short times are used, at relatively high potentials $\mathrm{CO}_{\mathrm{ads}}$ is partially oxidized by (likely) activated water. ${ }^{43}$ Afterwards, if the potential is stepped back to $0.10 \mathrm{~V}$ the oxygen-containing species desorbs and hydrogen is adsorbed. When high potentials are resumed the oxygen-containing species are quickly restored and the oxidation of the remaining $\mathrm{CO}_{\mathrm{ads}}$ continues as before, without being significantly affected, neither in $t_{i \text {, max }}$ nor $j_{\max }$. Therefore, our results indicate that apparently there is no shift of $\mathrm{CO}_{\mathrm{ads}}$ during its electrochemical oxidation, neither on cubic nor on octahedral Pt nanoparticles. Otherwise, in the intervals in which the potential is kept at $0.10 \mathrm{~V}$ (or at $0.45 \mathrm{~V}$ ), CO would diffuse toward preferential sites thus changing the oxidation profile in 
comparison to the experiment performed in a single potential step. Employing a sophisticated potential program, Kucernak and Offer ${ }^{44}$ have criticized the assumptions suggesting that $\mathrm{CO}_{\mathrm{ads}}$ presents mobility on a polycrystalline Pt surface. These authors proposed that $\mathrm{OH}_{\text {ads }}$ might diffuse to the immobile $\mathrm{CO}_{\mathrm{ads}}$, rather than $\mathrm{CO}_{\text {ads }}$ do to active sites. Because $\mathrm{CO}_{\mathrm{ads}}$ molecules in adlayer oxidation are apparently immobile species, such $\mathrm{CO}$ adlayer behaves as a poisoning layer on the electrode surface.

\section{Conclusions}

Regarding the $\mathrm{CO}_{\text {ads }}$ surface mobility and oxidation of this molecule on shapecontrolled Pt nanoparticles, we conclude that:

i. Experiments of $\mathrm{CO}$ sub-adlayer growth show that on octahedral Pt nanoparticles $\mathrm{CO}$ presents a slight preference for the adsorption on low coordination sites. This suggests that $\mathrm{CO}_{\mathrm{ads}}$ can slightly diffuse from $\{111\}$ terraces to low coordination sites. Conversely, on cubic Pt nanoparticles, $\mathrm{CO}_{\text {ads }}$ mobility is apparently very low.

ii. In CO stripping potentiostatic experiments, current-time curves show a similar profile for the oxidation of $\mathrm{CO}$, regardless the use of single or multiple oxidation steps. This suggests that $\mathrm{CO}_{\text {ads }}$ likely does not move towards the most catalytic active sites during the electro-oxidation of its adlayer. Adsorbed $\mathrm{CO}$ molecules behave as an adlayer poison on the catalyst surfaces during its oxidation. Hence, once a CO adlayer is formed, it remains motionless until it is fully oxidized either in octahedral or cubic Pt nanoparticles. From a reaction mechanism point of view, this implies that likely the oxygen-containing species reacts at the perimeter of the $\mathrm{CO}_{\mathrm{ads}}$ islands, rather than $\mathrm{CO}_{\mathrm{ads}}$ diffuses to the oxygen-containing species present at low coordination sites. 
Acknowledgements: M.J.S. Farias is grateful to the CAPES/PNPD (Brazil) for the financial support. G.A. Camara acknowledges CNPq (grants № 405695/2013-6 and 309176/2015-8) and FUNDECT (grants № 23/200.583/2012). J. M. Feliu thanks to the MINECO (Spain) project CTQ2016-76221-P. 


\section{References}

(1). Chen, Q. S.; Solla-Gullón, J.; Sun, S. G.; Feliu, J. M., The Potential of Zero Total Charge of Pt Nanoparticles and Polycrystalline Electrodes with Different Surface Structure: The Role of Anion Adsorption in Fundamental Electrocatalysis. Electrochim. Acta 2010, 55, 7982-7994.

(2). Iwasita, T.; Camara, G. A., Contributions of External Reflection Infrared Spectroscopy to Study the Oxidation of Small Organic Molecules. In In-Situ Spectroscopic Studies of Adsorption at the Electrode and Electrocatalysis, 2007; pp 33-61.

(3). Garcia, A. C.; Paganin, V. A.; Ticianelli, E. A., CO Tolerance of PdPt/C and PdPtRu/C Anodes for Pemfc. Electrochim. Acta 2008, 53, 4309-4315.

(4). Solla-Gullón, J.; Vidal-Iglesias, F. J.; Herrero, E.; Feliu, J. M.; Aldaz, A., CO Monolayer Oxidation on Semi-Spherical and Preferentially Oriented (100) and (111) Platinum Nanoparticles. Electrochem. Commun. 2006, 8, 189-194.

(5). Lai, S. C. S.; Lebedeva, N. P.; Housmans, T. H. M.; Koper, M. T. M., Mechanisms of Carbon Monoxide and Methanol Oxidation at Single-Crystal Electrodes. Top. Catal. 2007, 46, 320-333.

(6). Koper, M. T. M., Structure Sensitivity and Nanoscale Effects in Electrocatalysis. Nanoscale 2011, 3, 2054-2073.

(7). Maillard, F.; Eikerling, M.; Cherstiouk, O. V.; Schreier, S.; Savinova, E.; Stimming, U., Size Effects on Reactivity of Pt Nanoparticles in CO Monolayer Oxidation: The Role of Surface Mobility. Faraday Discuss. 2004, 125, 357-377.

(8). Gilman, S., The Mechanism of Electrochemical Oxidation of Carbon Monoxide and Methanol on Platinum. II. The "Reactant-Pair" Mechanism for Electrochemical Oxidation of Carbon Monoxide and Methanol. J. Phys. Chem. 1964, 68, 70-80.

(9). Koper, M. T.; Lai, S. C.; Herrero, E., Mechanisms of the Oxidation of Carbon Monoxide and Small Organic Molecules at Metal Electrodes. In Fuel Cell Catalysis: A Surface Science Approach, 2008; pp 159-207.

(10). Lebedeva, N. P.; Koper, M. T. M.; Feliu, J. M.; Van Santen, R. A., Role of Crystalline Defects in Electrocatalysis: Mechanism and Kinetics of CO Adlayer Oxidation on Stepped Platinum Electrodes. J. Phys. Chem. B 2002, 106, 1293812947.

(11). Petukhov, A. V., Effect of Molecular Mobility on Kinetics of an Electrochemical Langmuir-Hinshelwood Reaction. Chem. Phys. Lett. 1997, 277, 539-544.

(12). Bandarenka, A. S.; Koper, M. T. M., Structural and Electronic Effects in Heterogeneous Electrocatalysis: Toward a Rational Design of Electrocatalysts. J. Catal. 2013, 308, 11-24.

(13). Dubau, L.; Nelayah, J.; Moldovan, S.; Ersen, O.; Bordet, P.; Drnec, J.; Asset, T.; Chattot, R.; Maillard, F., Defects Do Catalysis: CO Monolayer Oxidation and Oxygen Reduction Reaction on Hollow PtNi/C Nanoparticles. ACS Catal. 2016, 6, 4673-4684.

(14). Wang, H.; Jusys, Z.; Behm, R. J.; Abruña, H. D., New Insights into the Mechanism and Kinetics of Adsorbed CO Electrooxidation on Platinum: Online Mass Spectrometry and Kinetic Monte Carlo Simulation Studies. J. Phys. Chem. C 2012, 116, 11040-11053.

(15). Roca-Ayats, M.; García, G.; Galante, J. L.; Peña, M. A.; Martínez-Huerta, M. V., Tic, Ticn, and Tin Supported Pt Electrocatalysts for $\mathrm{CO}$ and Methanol Oxidation in Acidic and Alkaline Media. J. Phys. Chem. C 2013, 117, 2076920777. 
(16). García, G.; González-Orive, A.; Roca-Ayats, M.; Guillén-Villafuerte, O.; Planes, G. Á.; Martínez-Huerta, M. V.; Hernández-Creus, A.; Pastor, E., Platinum Border Atoms as Dominant Active Site During the Carbon Monoxide Electrooxidation Reaction. Int. J. Hydrogen Energy 2016, 41, 19674-19683.

(17). Farias, M. J. S.; Herrero, E.; Feliu, J. M., Site Selectivity for CO Adsorption and Stripping on Stepped and Kinked Platinum Surfaces in Alkaline Medium. $J$. Phys. Chem. C 2013, 117, 2903-2913.

(18). Farias, M. J. S.; Camara, G. A.; Feliu, J. M., Understanding the CO Preoxidation and the Intrinsic Catalytic Activity of Step Sites in Stepped Pt Surfaces in Acidic Medium. J. Phys. Chem. C 2015, 119, 20272-20282.

(19). Love, B.; Lipkowski, J., Effect of Surface Crystallography on Electrocatalytic Oxidation of Carbon Monoxide on Platinum Electrodes. In Electrochemical Surface Science, American Chemical Society: 1988; Vol. 378, pp 484-496.

(20). Villegas, I.; Weaver, M. J., Carbon Monoxide Adlayer Structures on Platinum (111) Electrodes: A Synergy between in-Situ Scanning Tunneling Microscopy and Infrared Spectroscopy. J. Chem. Phys. 1994, 101, 1648.

(21). Wakisaka, M.; Yoneyama, T.; Ashizawa, S.; Hyuga, Y.; Ohkanda, T.; Uchida, H.; Watanabe, M., Structural Variations of CO Adlayers on a Pt(100) Electrode in $0.1 \mathrm{M} \mathrm{HClO}_{4}$ Solution: An in situ STM Study. Phys. Chem. Chem. Phys. 2013, 15, 11038-11047.

(22). Chang, S. C.; Weaver, M. J., Coverage-Dependent Dipole Coupling for Carbon Monoxide Adsorbed at Ordered Platinum (111)-Aqueous Interfaces: Structural and Electrochemical Implications. J. Chem. Phys. 1990, 92, 4582.

(23). Coutanceau, C.; Urchaga, P.; Baranton, S., Diffusion of Adsorbed CO on Platinum (100) and (111) Oriented Nanosurfaces. Electrochemistry Communications 2012, 22, 109-112.

(24). Seung, W. L.; Chen, S.; Sheng, W.; Yabuuchi, N.; Kim, Y. T.; Mitani, T.; Vescovo, E.; Shao-Horn, Y., Roles of Surface Steps on Pt Nanoparticles in Electro-Oxidation of Carbon Monoxide and Methanol. J. Am. Chem. Soc. 2009, 131, 15669-15677.

(25). Brimaud, S.; Pronier, S.; Coutanceau, C.; Léger, J. M., New Findings on CO Electrooxidation at Platinum Nanoparticle Surfaces. Electrochem. Commun. 2008, 10, 1703-1707.

(26). Solla-Gullón, J.; Rodríguez, P.; Herrero, E.; Aldaz, A.; Feliu, J. M., Surface Characterization of Platinum Electrodes. Phys. Chem. Chem. Phys. 2008, 10, 1359-1373.

(27). Farias, M. J. S.; Vidal-Iglesias, F. J.; Solla-Gullón, J.; Herrero, E.; Feliu, J. M., On the Behavior of CO Oxidation on Shape-Controlled Pt Nanoparticles in Alkaline Medium. J. Electroanal. Chem. 2014, 716, 16-22.

(28). Vidal-Iglesias, F. J.; Arán-Ais, R. M.; Solla-Gullón, J.; Herrero, E.; Feliu, J. M., Electrochemical Characterization of Shape-Controlled Pt Nanoparticles in Different Supporting Electrolytes. ACS Catal. 2012, 2, 901-910.

(29). Zhou, Z.-Y.; Tian, N.; Li, J.-T.; Broadwell, I.; Sun, S.-G., Nanomaterials of High Surface Energy with Exceptional Properties in Catalysis and Energy Storage. Chem. Soc. Rev. 2011, 40, 4167-4185.

(30). Urchaga, P.; Baranton, S.; Coutanceau, C., Changes in $\mathrm{CO}_{\text {chem }}$ Oxidative Stripping Activity Induced by Reconstruction of Pt (111) and (100) Surface Nanodomains. Electrochim. Acta 2013, 92, 438-445. 
(31). Urchaga, P.; Baranton, S.; Coutanceau, C.; Jerkiewicz, G., Evidence of an EleyRideal Mechanism in the Stripping of a Saturation Layer of Chemisorbed CO on Platinum Nanoparticles. Langmuir 2012, 28, 13094-13104.

(32). Lebedeva, N. P.; Koper, M. T. M.; Feliu, J. M.; Van Santen, R. A., Mechanism and Kinetics of the Electrochemical CO Adlayer Oxidation on $\operatorname{Pt}(111) . J$. Electroanal. Chem. 2002, 524-525, 242-251.

(33). Brimaud, S.; Jusys, Z.; Jürgen Behm, R., Shape-Selected Nanocrystals for in Situ Spectro-Electrochemistry Studies on Structurally Well Defined Surfaces under Controlled Electrolyte Transport: A Combined in situ ATR-FTIR/Online DEMS Investigation of CO Electrooxidation on Pt. Beilstein J. Nanotechnology 2014, 5, 735-746.

(34). Liu, H.-X.; Tian, N.; Ye, J.-Y.; Lu, B.-A.; Ren, J.; Huangfu, Z.-C.; Zhou, Z.-Y.; Sun, S.-G., A Comparative Study of CO Adsorption on Tetrahexahedral Pt Nanocrystals and Interrelated Pt Single Crystal Electrodes by Using Cyclic Voltammetry and in situ FTIR Spectroscopy. Faraday Discuss. 2014, 176, 409428.

(35). Farias, M. J. S.; Tanaka, A. A.; Tremiliosi-Filho, G.; Feliu, J. M., On the Apparent Lack of Preferential Site Occupancy and Electrooxidation of CO Adsorbed at Low Coverage onto Stepped Platinum Surfaces. Electrochem. Commun. 2011, 13, 338-341.

(36). Xu, M.; Liu, J.; Zaera, F., Kinetic Evidence for the Dependence of Surface Reaction Rates on the Distribution of Reactants on the Surface. J. Chem. Phys. 1996, 104, 8825-8828.

(37). Zaera, F., Kinetics of Chemical Reactions on Solid Surfaces: Deviations from Conventional Theory. Acc. Chem. Res. 2002, 35, 129-136.

(38). Ertl, G., Heterogeneous Catalysis on the Atomic Scale. Chem. Rec. 2001, 1, 3345.

(39). Lin, T. H.; Somorjai, G. A., Modulated Molecular Beam Scattering of CO and NO from Pt(111) and the Stepped Pt(557) Crystal Surfaces. Surf. Sci. 1981, 107, 573-585.

(40). Tränkenschuh, B.; Papp, C.; Fuhrmann, T.; Denecke, R.; Steinrück, H. P., The Dissimilar Twins - A Comparative, Site-Selective in situ Study of CO Adsorption and Desorption on Pt(322) and Pt(355). Surf. Sci. 2007, 601, 11081117.

(41). Tränkenschuh, B.; Fritsche, N.; Fuhrmann, T.; Papp, C.; Zhu, J. F.; Denecke, R.; Steinrück, H. P., A Site-Selective in situ Study of $\mathrm{CO}$ Adsorption and Desorption on Pt(355). J. Chem. Phys. 2006, 124.

(42). Vattuone, L.; Savio, L.; Rocca, M., Bridging the Structure Gap: Chemistry of Nanostructured Surfaces at Well-Defined Defects. Surf. Sci. Rep. 2008, 63, 101168.

(43). Batista, E. A.; Iwasita, T.; Vielstich, W., Mechanism of Stationary Bulk CO Oxidation on Pt(111) Electrodes. J. Phys. Chem. B 2004, 108, 14216-14222.

(44). Kucernak, A. R.; Offer, G. J., The Role of Adsorbed Hydroxyl Species in the Electrocatalytic Carbon Monoxide Oxidation Reaction on Platinum. Phys. Chem. Chem. Phys. 2008, 10, 3699-3711. 


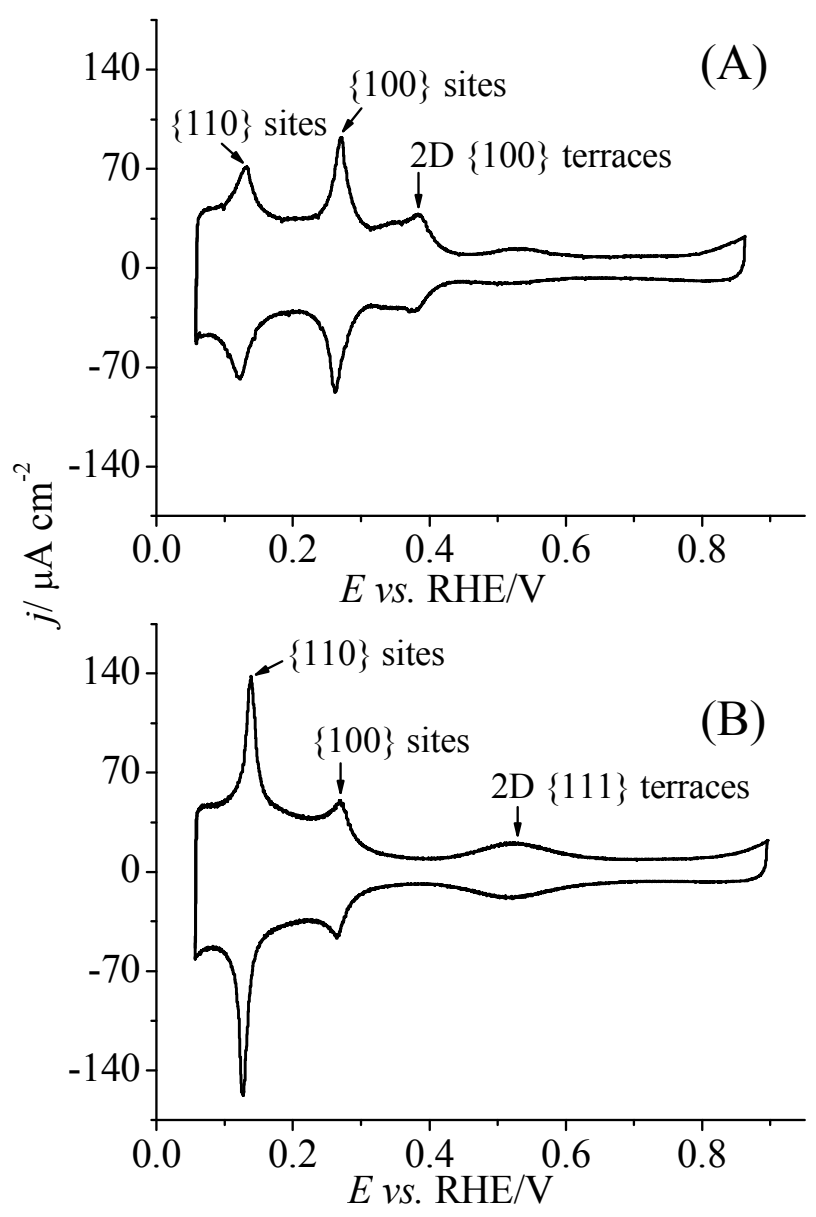

Figure 1. Cyclic voltammograms of cubic (A) and octahedral (B) Pt nanoparticles obtained at $0.05 \mathrm{~V} \mathrm{~s}^{-1}$ in $0.5 \mathrm{M} \mathrm{H}_{2} \mathrm{SO}_{4}$. 

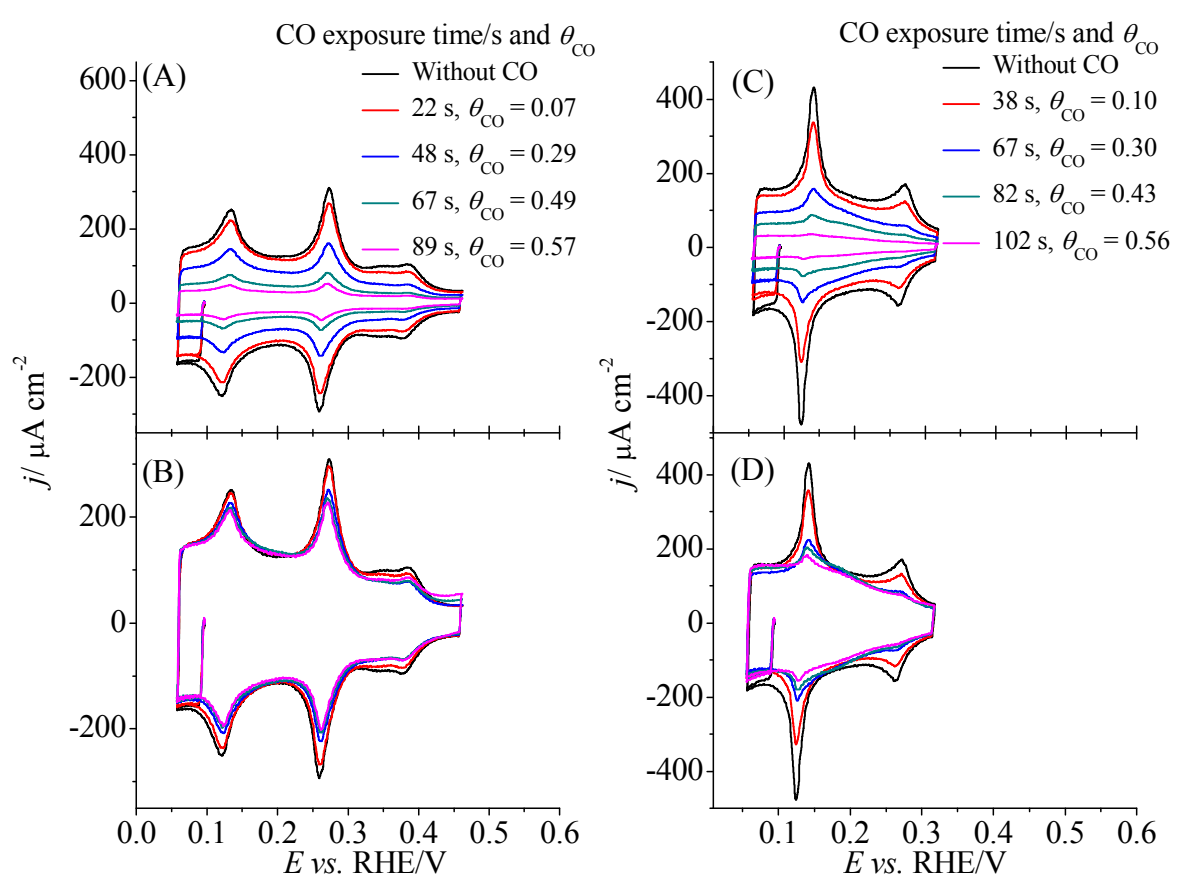

Figure 2. Cyclic voltammograms $(0.060 \mathrm{~V} \leq E \leq 0.460 \mathrm{~V})$ recorded at $0.2 \mathrm{~V} \mathrm{~s}^{-1}$ after potentiostatic growth (at $0.100 \mathrm{~V}$ ) of the $\mathrm{CO}$ sub-adlayer: $(\mathrm{A})$ cubic and $(\mathrm{C})$ octahedral Pt nanoparticles. In (B) and (D) the original current values were adjusted from the data in panel (A) and (C), respectively, to purposes of visualization. Different times of CO exposure correspond to different $\theta_{\mathrm{CO}}$. 


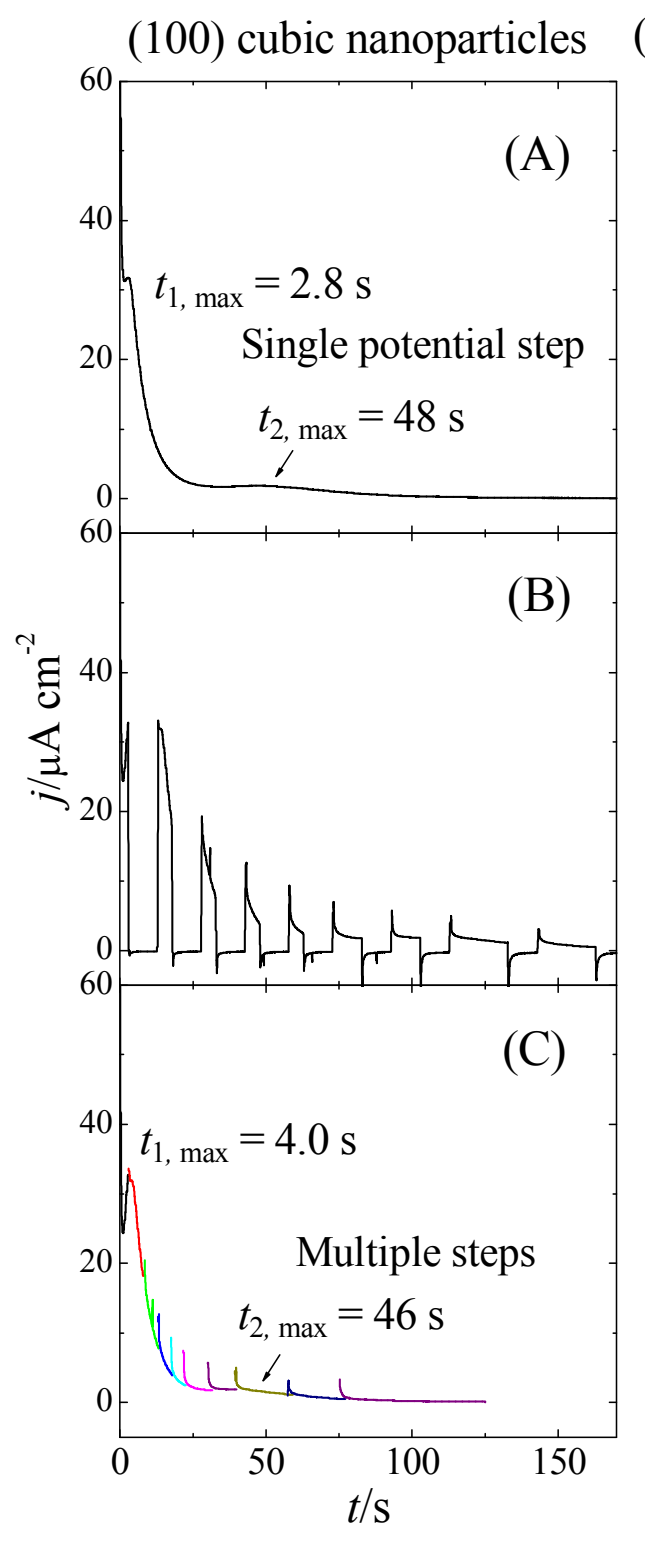

(111) octahedral nanoparticles

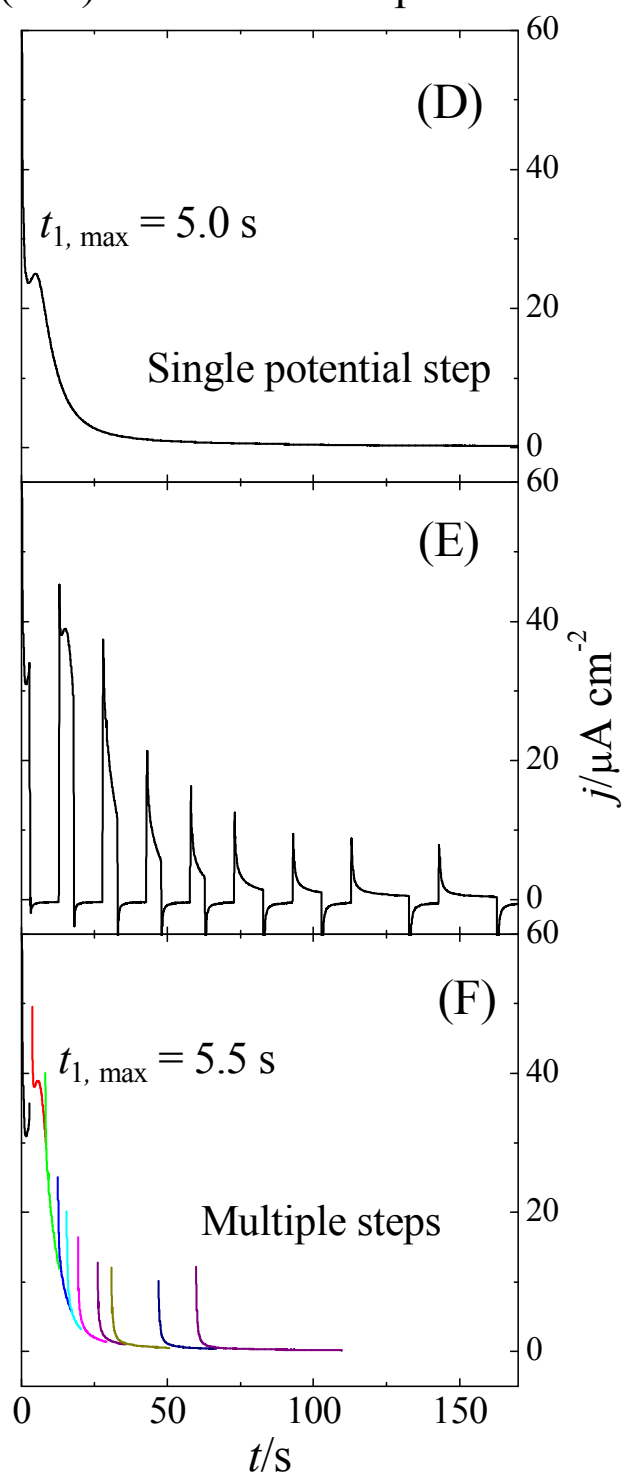

Figure 3. Potential step chronoamperometries of oxidation of a $\mathrm{CO}$ adlayer on $\mathrm{Pt}$ cubic (A, B and C) and Pt octahedral (D, E and F) nanoparticles, when $\mathrm{CO}$ was adsorbed at $0.10 \mathrm{~V}$. The panels A and D panels show current $v$ s time curves performed in a single potential step from $0.10 \mathrm{~V}$ to $0.65 \mathrm{~V}$. The panels $\mathrm{B}$ and $\mathrm{E}$ show successive potential steps for a partial oxidation of a $\mathrm{CO}$ adlayer, according to the sequence $0.10 \mathrm{~V} \rightarrow 0.65 \mathrm{~V}$ $\rightarrow 0.10 \mathrm{~V} \rightarrow 0.65 \mathrm{~V} \ldots$. The panels $\mathrm{C}$ and $\mathrm{F}$ show the resulting current $v s$ time curves performed in multiple steps after the subtraction of the currents collected at $0.10 \mathrm{~V}$ from Figures $3 \mathrm{~B}$ and $3 \mathrm{E}$. All the experiments were performed in $0.5 \mathrm{M} \mathrm{H}_{2} \mathrm{SO}_{4}$. 


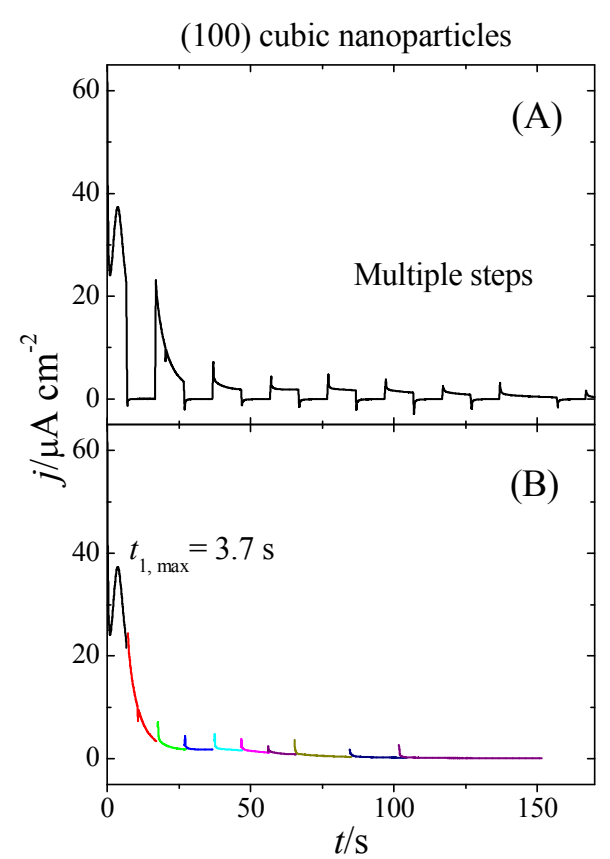

(111) octahedral nanoparticles

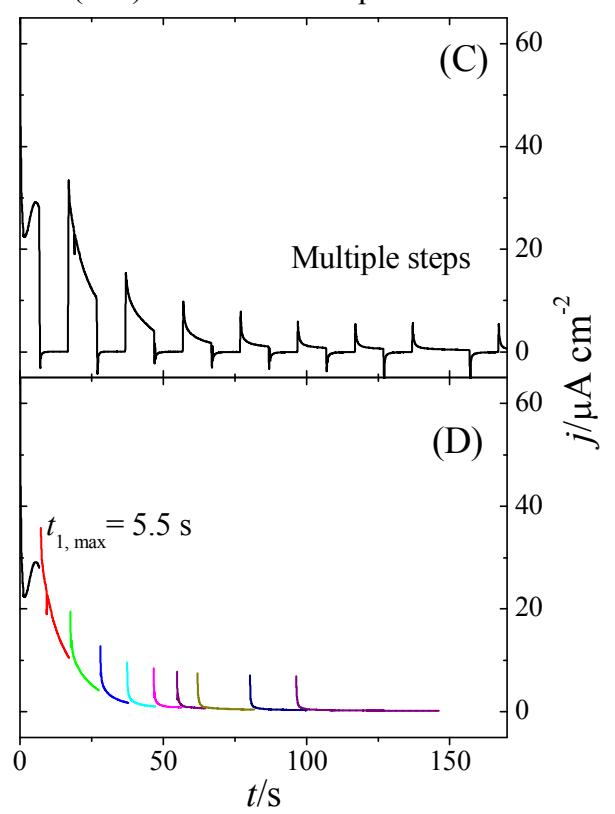

Figure 4. Potential step chronoamperometries of CO stripping off. The panels A and C show current $v s$ time curves performed in multiple potential steps from 0.10 to $0.65 \mathrm{~V}$, and back to $0.45 \mathrm{~V}$ successively according to the sequence $0.10 \mathrm{~V} \rightarrow 0.65 \mathrm{~V} \rightarrow 0.45 \mathrm{~V}$ $\rightarrow 0.65 \mathrm{~V} \rightarrow 0.45 \mathrm{~V} \ldots$ for Pt cubic and octahedral nanoparticles. The panels B and D show the resulting current $v s$ time curves for cubic and octahedral Pt particles, respectively, performed in multiple steps after the subtraction of the currents collected at $0.45 \mathrm{~V}$ from Figures $4 \mathrm{~A}$ and $4 \mathrm{C}$. All the experiments were performed in $0.5 \mathrm{M}$ $\mathrm{H}_{2} \mathrm{SO}_{4}$. 


\section{TOC Graphical}

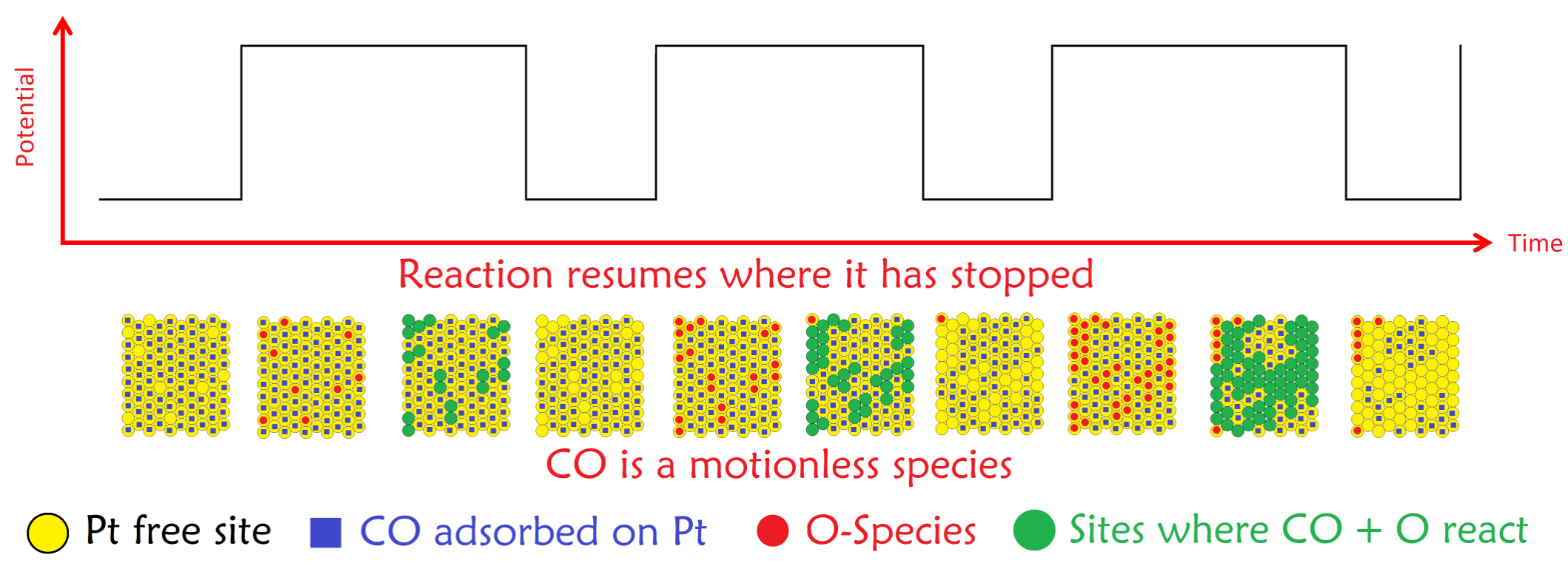


